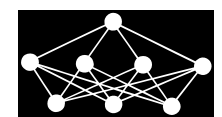

\title{
FUZZY LOGIC MODEL OF IRRADIATED AGGREGATES
}

\author{
M. Vaitová*, P. Štemberk $\dagger^{\dagger}$ T. M. Rosseel
}

\begin{abstract}
The worldwide need for nuclear power plant (NPP) lifetime extension to meet future national energy requirements while reducing greenhouse gases raises the question of the condition of concrete structures exposed to ionizing radiation. Although research into the effects of radiation has a long history and the phenomenon of deterioration of concrete due to irradiation is not yet completely understood, the main assumed degradation mode is radiation-induced volumetric expansion of aggregates. There are experimental data on irradiated concrete obtained over decades under different conditions; however, the collection of data exhibits considerable scatter. Fuzzy logic modeling offers an effective tool that can interconnect various data sets obtained by different teams of experts under different conditions. The main goal of this work is to utilize available data on irradiated concrete components such as minerals and aggregates that expand upon irradiation. Furthermore, aggregate radiation-induced volumetric expansion gives an estimate of the change in mechanical properties of aggregate after years of reactor operation. The mechanical properties of irradiated aggregate can then be used for modeling irradiated concrete in the actual NPP structure based on the composition of concrete, the average temperature on the surface of the biological shield structure, and the neutron dose received by biological shield.
\end{abstract}

Key words: irradiated minerals, irradiated aggregate, radiation induced expansion, fuzzy logic model

Received: October 18, 2016

DOI: $10.14311 / N N W .2019 .29 .001$

Revised and accepted: January 17, 2019

\section{Introduction}

Since the 1950's the nuclear industry has undergone an extensive development of technologies and equipment in its facilities. However, one of the most important components has not changed significantly: the biological shield and the structural material used for its construction. Even though concrete is an extremely variable

\footnotetext{
* Michaela Vaitová - Corresponding author; Czech Technical University in Prague, Faculty of Civil Engineering, Thákurova 7/2077, CZ-166 29 Praha 6, Czech Republic, E-mail: michaela. vaitova@fsv.cvut.cz

${ }^{\dagger}$ Petr Štemberk; Czech Technical University in Prague, Faculty of Civil Engineering, Thákurova 7/2077, CZ-166 29 Praha 6, Czech Republic, E-mail: stemberk@fsv.cvut.cz

$\ddagger$ Thomas M. Rosseel; Oak Ridge National Laboratory, Materials Science and Technology Division, 1 Bethel Valley Rd, Oak Ridge, TN 37831, USA, E-mail: rosseeltm@ornl.gov
} 
material usually containing aggregates from local sources, the material heterogeneity is not surprising to civil engineers who work mainly with concrete as a homogeneous material. Since the biological shield has a shielding and in many instances also a load-bearing function, the material condition and soundness are the essential criteria for safe reactor operation, Fig. 1. The worldwide need for license renewal of nuclear facilities has raised the question of what are the effects of radiation on concrete. The community of researchers has attempted to find the answer since the very beginning of the nuclear era in 1960's and 1970's as summarized in [6]. The major conclusion of their research was that neutron fluences above $10^{19} \mathrm{n} \cdot \mathrm{cm}^{-2}$, not specifying energy spectrum of neutrons, cause a reduction of mechanical properties, $[6,13,8]$. They also discovered that some aggregates (granite, gabbro, sandstone, etc.) are more susceptible to radiation effects than other aggregates and may increase in volume significantly, $[14,2,7,3,11,16]$. Currently, the neutron fluence received on the biological shielding exceeds the threshold in 40 or more years of operation for 2-loop pressurized water reactors (PWR) which is the smallest unit designed and built by Westinghouse, [4].

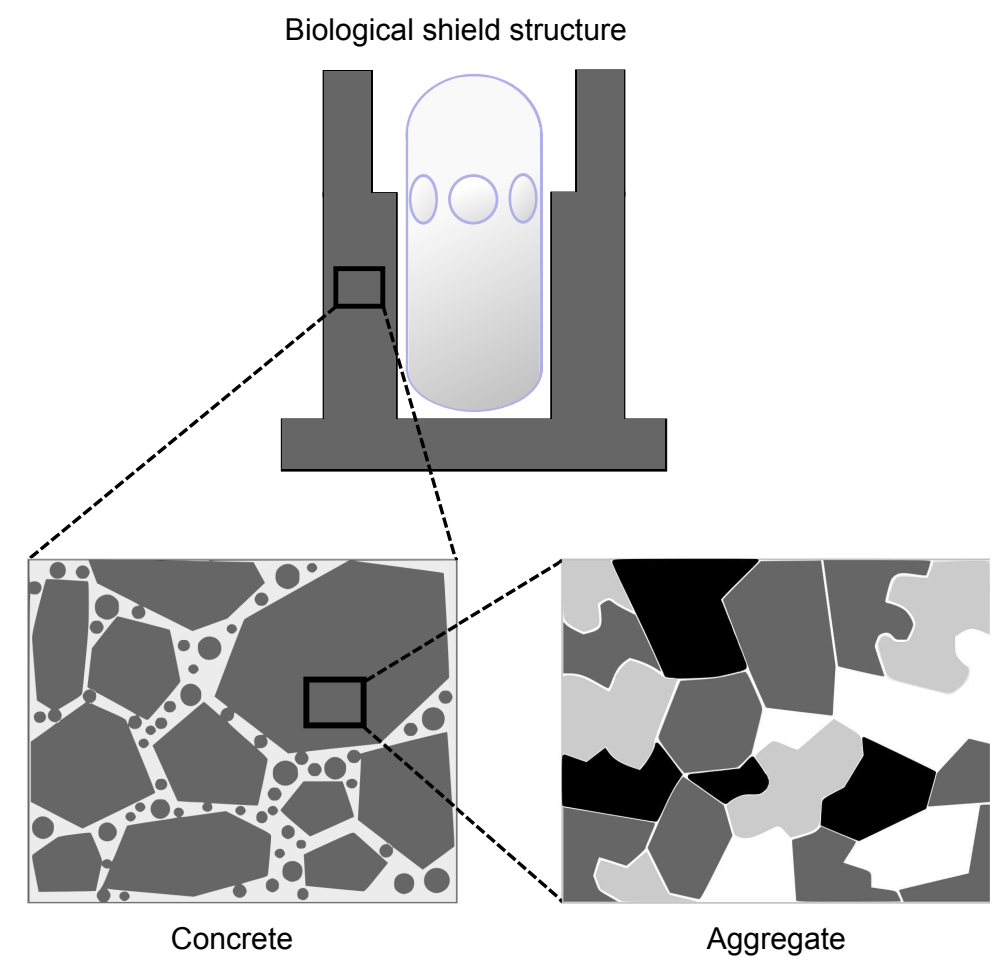

Fig. 1 Biological shield structural material.

The collection of irradiated concrete data shows a large scatter which is thought to be due to different testing conditions and material composition, [6, 14]. Therefore, deeper understanding of testing conditions as well as materials composition on concrete properties, is crucial for a comprehensive assessment of the condition of a biological shielding structure. 
Vaitová M., Štemberk P., Rosseel T.M.: Fuzzy logic model of irradiated...

Not only is concrete a composite or multiphase material, but the aggregates used in concrete are composed of minerals that exhibit radiation-induced volumetric expansion (RIVE) as shown in Fig. 2. That is why minerals deserve attention in order to understand the overall effects of radiation on concrete. Minerals determine the resulting behavior of irradiated aggregate, which in turn determines the behavior of the irradiated concrete. It seems that step-by-step upscaling of the material behavior is the proper method that leads to obtaining the concrete properties after years of irradiation.

Since the data used for the development of the model are limited, the fuzzy logic approach is utilized for the same reasons as in the previous work [15, 10].

The following section of the paper describes a fuzzy logic model that uses the trends of mineral radiation-induced expansion for determining the expansion of irradiated aggregates.

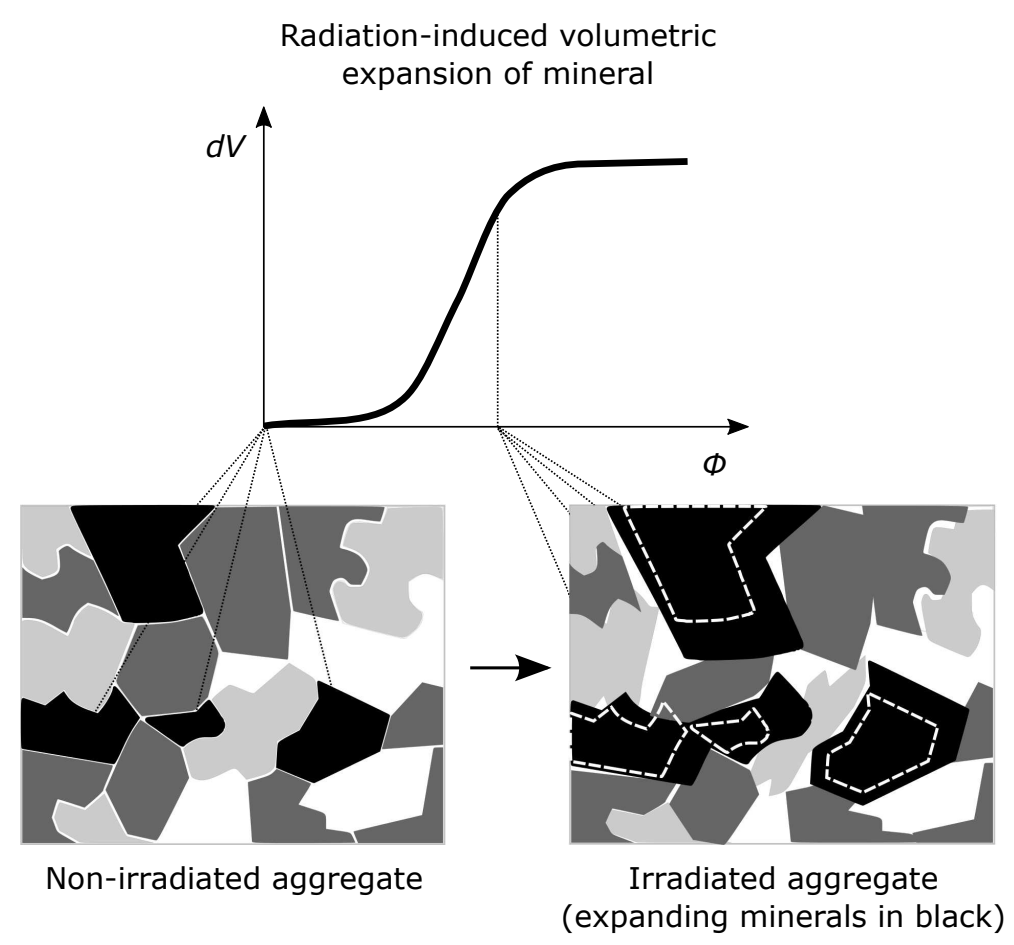

Fig. 2 Example of radiation-induced volumetric expansion (RIVE) of one mineral within the aggregate.

\section{Available data on aggregate expansion}

Concrete is a composite material consisting of two main phases which are the aggregates and the cement paste. Since the predominant effect of deterioration of concrete properties is assumed to be the RIVE of aggregates, and since aggregates 
occupy $60-80 \%$ of concrete volume, [9], the main focus in the modeling is on the aggregate behavior upon irradiation.

The aggregate itself consists of minerals which suggests that the aggregate could be viewed as a composite or multiphase material. In the same manner as the aggregates affect concrete properties, the aggregate properties are derived from its component minerals.

Since the change of mechanical properties of aggregates is related to dimensional changes, an estimate of dimensional changes of aggregates induced by radiation is the crucial step to determine the resulting mechanical properties. The driving parameters for aggregate RIVE besides the radiation dose consist of the types of minerals in the aggregate, their concentration, irradiation temperature and the aggregate structure. Therefore, the main input to an aggregate expansion model is the expansion of the component minerals. Since minerals expand differently under various temperatures, the expansion of minerals has to be controlled also by temperature, as shown in Fig. 3, where the issues related to the quality and quantity of the experimental data can be understood. Futhermore, mineral expansion is limited by the saturation point which is the ultimate defect accumulation.

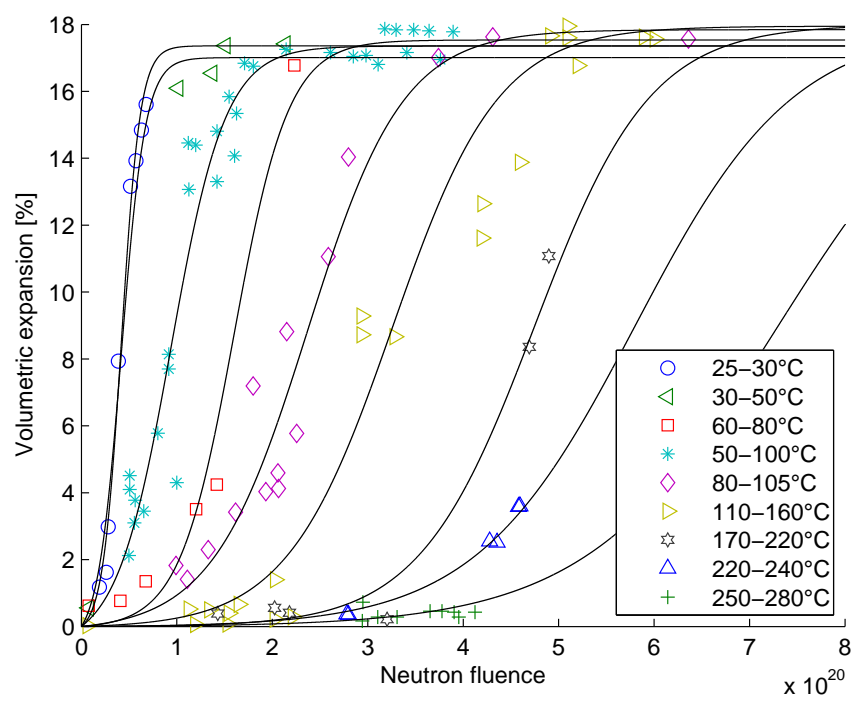

Fig. 3 Radiation-induced expansion of quartz - experimental data [2].

An extensive compilation of experimental data on the dependence of aggregate mechanical properties due to RIVE can be found in [2]. It demonstrates that the volumetric expansion of aggregates can be used to estimate the change of mechanical properties of aggregates or may be used as an input into a meso-scale model of concrete using a finite element method [5]. Clearly, the density, strength and stiffness of aggregates decrease with increasing volume and crack development.

Irradiated aggregates exhibit similar changes as polycrystalline minerals because of the similarity of defects developed in between the phases in minerals and the minerals in aggregates due to their different volumetric expansion, which even- 
Vaitová M., Štemberk P., Rosseel T.M.: Fuzzy logic model of irradiated...

tually leads to cracks, as shown in Fig. 2. The one-dimensional changes of irradiated aggregates can be as large as $7 \%$ resulting in volumetric expansion up to $23 \%$ [2]. The contribution of cracking in the overall volumetric changes can be greater than $67 \%$ of the overall volumetric changes which implies that cracking has a greater impact on the total expansion than the expansion of minerals [2]. A significant portion of cracking causes reduction in the mechanical properties of aggregates. This effect is best exhibited by the decrease in the modulus of elasticity with radiationinduced damage. Even though the compressive and tensile strength also exhibit decrease, the change is not as significant.

The radiation induced effects in aggregates depend on neutron fluence and energy spectrum, temperature and the structure and atomic bonding of the aggregates. The composition and structure of aggregates affect the susceptibility to defect formation.

Since the minerals that exhibit the largest expansion are silicates, aggregates with siliceous minerals are the most susceptible to RIVE [2, 14]. Detailed information concerning volumetric expansion and changes in mechanical properties of selected siliceous aggregates is shown in Tab. I.

\begin{tabular}{lccc}
\hline Aggregate & Main minerals & $\begin{array}{c}\text { Volumetric } \\
\text { expansion } \\
{[\%]}\end{array}$ & $\begin{array}{c}\text { Mechanical } \\
\text { properties } \\
\text { decrease [\%] }\end{array}$ \\
\hline $\begin{array}{l}\text { granite, granodiorite, } \\
\text { diorite, quarzitic syen- } \\
\text { ite, sandstone, aleuro- } \\
\text { lite }\end{array}$ & quartz, feldspar & 23.0 & $90.0-100.0$ \\
\hline $\begin{array}{l}\text { gabbro, basalt, diabas, } \\
\text { pyroxenite }\end{array}$ & $\begin{array}{c}\text { pyroxene, } \\
\text { hornblende }\end{array}$ & 7.7 & 14.0 \\
\hline $\begin{array}{l}\text { olivinite, dunite, } \\
\text { serpentine }\end{array}$ & $\begin{array}{c}\text { olivine, serpentine, } \\
\text { silica ceramic } \\
\text { containing glass }\end{array}$ & 3.0 & $\begin{array}{c}\text { no } \\
\text { significant } \\
\text { changes }\end{array}$ \\
\hline
\end{tabular}

Tab. I Siliceous aggregates composition and observed radiation-induced changes in properties [2].

The essential issue of understanding the effects of radiation damage in concrete is therefore the formation of radiation-induced defects in minerals. Neutrons interacting with atoms in a crystalline lattice cause displacement of atoms which results in vacancies, interstitial atoms or substitution of one atom with another. According to the experimental data, the energy range of neutrons causing the damage varies primarily from 0.01 to $1 \mathrm{MeV}$ [2]. Furthermore, Remec's calculations [12] identified the observed cut-off energy of neutrons causing greater than $95 \%$ of the damage as $\mathrm{E}>0.1 \mathrm{MeV}$. The accumulation of defects in well-crystalized materials (minerals - quartz, feldspar, biotite, etc.) caused by irradiation are amorphization, partial or complete transformation into other minerals, anisotropic changes in crystalline lattice, and changes in physical properties. 
The mineral properties studied by most researchers are the changes in density, crystalline lattice parameters, dimension, coefficient of thermal expansion, and other optical properties that do not necessarily reflect the impact of radiation on mechanical properties. From the mechanical properties point of view, the most interesting effect is the dimensional change of minerals. The anisotropic nature of dimensional change results in unequal expansion along different axes of crystal lattice. Accordingly, shrinkage may take place in certain directions while in other directions the mineral expands.

The available data $[6,4,2]$ demonstrate that radiation expansion increases until it reaches the saturation point which means the ultimate concentration of defects. For that reason, radiation-induced expansion of minerals is usually described by a sigmoid function. For silicates, the sigmoidal behavior of the expansion of aggregates as a function of the neutron fluence is affected significantly by the temperature during irradiation as shown in Fig. 3. The higher the temperature, the higher the neutron fluence needed to reach the maximum of the sigmoid function [2]. This phenomenon is caused by the partial annealing of the material exposed to high temperatures and seems especially significant in silicates [2].

\section{Fuzzy logic model}

\subsection{General strategy}

Since the use of statistics would be dubious for the available experimental data, which were obtained under poorly defined temperature conditions, it was decided to use the fuzzy logic to propagate the uncertainty contained in the experimental data for the minerals into estimates of RIVE of various aggregate types. The fuzzy logic helped to define the validity of the scatter of the experimental data of RIVE with respect to the temperature range. The concept of definition of a fuzzy set, or a fuzzy number, which expresses the uncertainty of the RIVE estimate with respect to temperature is shown in Fig. 4 where $\mu$ is the degree of membership, $\phi$ is the neutron fluence and $d V$ is volumetric expansion.

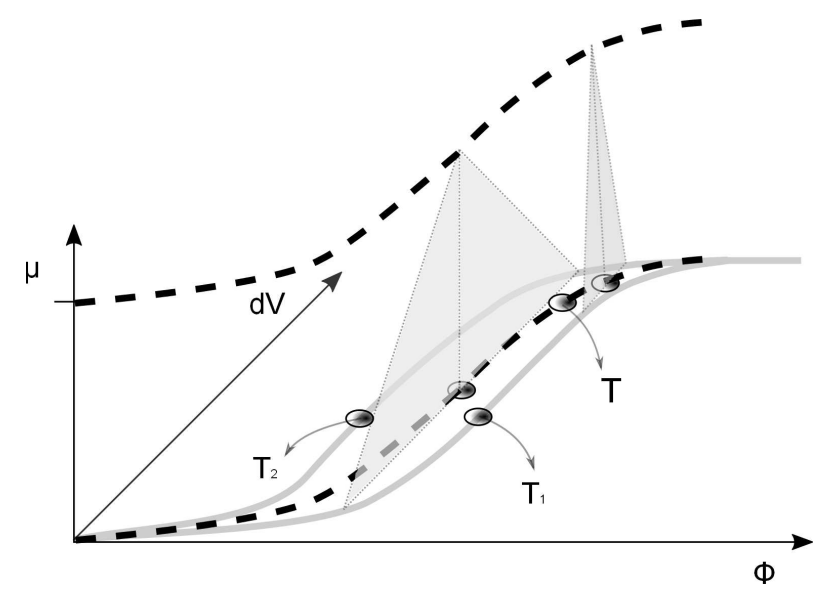

Fig. 4 Fuzzy number of RIVE of mineral under uncertain temperature. 
The general strategy is to define a measure of validity of a RIVE estimate, using the shape of a fuzzy set, which is based on the definition of the lower and the upper bound of the RIVE over the temperature range, Fig. 4. The lower and the upper bound are then evaluated using the coefficient of determination in order to take into account the effect of temperature on the validity of the experimentally obtained RIVE of each mineral at a given fluence. The coefficient of determination $R^{2}$ is then used to define the shape of the fuzzy set. For example, when $R^{2}=1$ the resulting RIVE is valid for the entire range of temperatures and when $R^{2}=0$ the resulting RIVE is only an estimate valid for the average temperature; however, it has some limited validity over the range of the temperature, Fig. 5. These fuzzy sets are then used when the combined effect of temperature on the individual minerals is evaluated for a given aggregate type. In Fig. $5, L$ in is the difference between the highest and the lowest temperature for given irradiation data.

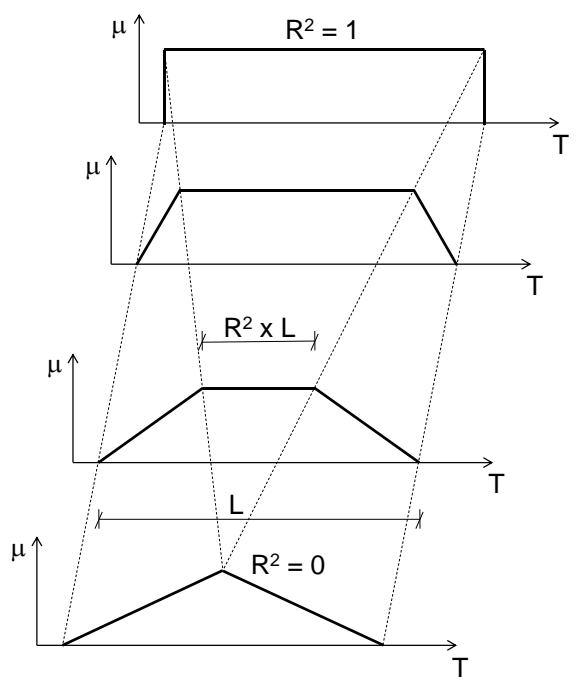

Fig. 5 Definition of shape of fuzzy set.

The resulting RIVE estimates for three aggregate types (granite, diorite and gabbro) from Fig. 6 and for three representative temperatures of $40^{\circ} \mathrm{C}, 80^{\circ} \mathrm{C}$ and $120^{\circ} \mathrm{C}$ are provided already as defuzzified in a form of surfaces, between which it is possible to interpolate in order to obtain intermediate values.

\subsection{Selection of valid sets of minerals}

The common aggregates used for concrete production are igneous rocks containing silica dioxide. Moreover the mineral expansion referenced in the literature, specifically [2], is mostly related to silicate minerals. Therefore, the experimental data on silicate minerals assembled by Denisov, [2], are used to create a model of radiation expansion of silicate igneous rocks such as granite, diorite and gabbro. According to the petrographic composition of these rocks, the behaviour of minerals namely quartz, plagioclase feldspar, orthoclase feldspar, augite(pyroxene), 
Neural Network World 1/2019, 1-18

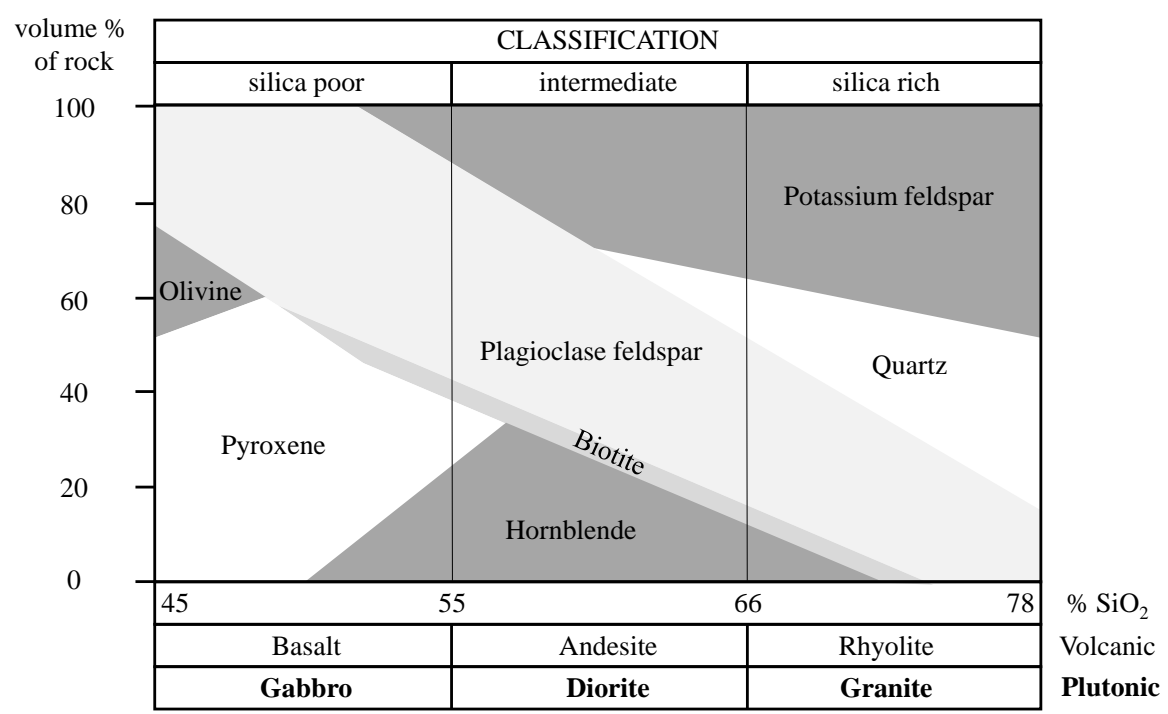

Fig. 6 Proportions of common minerals in different types of igneous rock, [1].

hornblende(amphibole), olivine, and mica, should be known. However, since the experimental data are limited the proper data set should be chosen for the model.

The most studied irradiated mineral is quartz which has the most extensive data set of all minerals, for example see Fig. 3. Then, the data for groups of minerals such as feldspars, pyroxene, and mica are represented by the most studied mineral within the group. Specifically, the representative mineral of plagioclase feldspars is oligoclase, for potassium feldspars the representative is microcline and finally for mica it is biotite. The only mineral which has such a poor reference that has to be omitted is olivine. Since the expansion of olivine was not greater than $1 \%$, it was excluded from the RIVE model.

\subsection{Built database of minerals}

In order to use mineral expansion data, the sigmoid curves for different temperature ranges are fitted to the data points based on the coefficient of determination $\left(\mathrm{R}^{2}\right)$. Each experimental data point was obtained within a known temperature range, therefore, each expansion curve is also given for a range of temperatures. The general formula of the sigmoid curve is

$$
d V_{(\phi)}=\frac{d V_{\max }}{1+\mathrm{e}^{-p(\phi-q)}}-r
$$

where $d V$ is volumetric expansion, $d V_{\max }$ is the maximum overall expansion of the mineral, $\phi$ is neutron fluence, and $p$ and $q$ are parameters describing the shape of the sigmoid curve, specifically, the slope and its position in the coordinate system. These parameters are summarized in Tab. II. The parameter $r$ shifts the function vertically so that it goes through the origin. It should be noted that all of the 
Vaitová M., Štemberk P., Rosseel T.M.: Fuzzy logic model of irradiated...

sigmoidal function parameters are strongly dependent on the temperature during irradiation.

\begin{tabular}{lccc}
\hline Silica minerals & $d V_{\max }$ & $p$ & $q$ \\
\hline quartz & $17.6-18$ & $1-10 \times 10^{-20}$ & $0.4-7.3 \times 10^{20}$ \\
pottasium feldspars & $7.4-8.2$ & $1.2-10 \times 10^{-20}$ & $0.7-4.5 \times 10^{20}$ \\
plagioclase feldspars & $7-7.2$ & $1.3-2.9 \times 10^{-20}$ & $1.2-5.3 \times 10^{20}$ \\
pyroxenes & $2.35-3.1$ & $2-7.2 \times 10^{-20}$ & $0.3-1.7 \times 10^{20}$ \\
biotite & 1.64 & $1 \times 10^{-20}$ & $1 \times 10^{20}$ \\
hornblende & $1.2-2.2$ & $1.7-7 \times 10^{-20}$ & $0.6-2 \times 10^{20}$ \\
\hline
\end{tabular}

Tab. II Fitting parameters of radiation-induced mineral expansion sigmoidal function.

Fig. 3 depicts the volumetric expansion of quartz, which is a mineral with the most data and therefore has the best reliability. The curves for different temperatures show the effect of annealing on the material upon irradiation. Specifically, the higher the temperature, the higher the radiation dose required to cause volumetric expansion. Furthermore, the change of the curve slope with temperature has a decreasing trend that is utilized in the aggregate expansion model where increasing temperature reduces the radiation-induced damage.

Fig. 7 depicts the volumetric expansion of an acidic plutonic magmatic aggregate, granite. The volumetric expansion for these rocks are known in the temperature ranges of $90-110^{\circ} \mathrm{C}$ and $115-160^{\circ} \mathrm{C}$ for low as well as high levels of neutron fluence, while the expansion at temperatures lower than $90^{\circ} \mathrm{C}$ is unknown for high

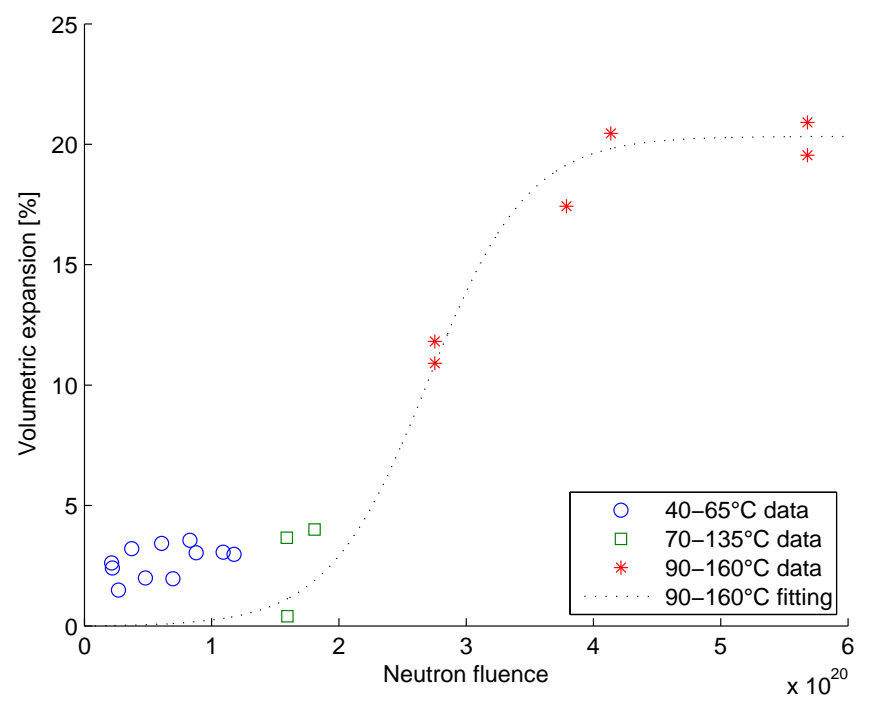

Fig. 7 Radiation-induced expansion of granite - experimental data [2]. 
neutron fluence. Therefore, the trends (Fig. 3) in mineral behavior at lower temperatures and high fluence can be extrapolated to obtain the volumetric expansion of aggregates at lower temperatures based on the fraction of minerals within the aggregates.

\subsection{Estimation of aggregate expansion}

The aggregates, as a multiphase material, are composed of different minerals, therefore, each mineral affects the aggregate behavior to a different degree. Specifically, the aggregate radiation-induced expansion is derived from the expansion of the component minerals.

Each aggregate has a specific mineral composition. For the aggregate behavior prediction, the content of minerals is the determining factor. Based on the similar shapes of the aggregate and mineral expansion curves (Fig. 3 and 7), it is assumed that the function used to describe radiation-induced expansion of minerals, Eq. (1), can also be utilized to describe the shape of the aggregate expansion curve and, thereby, provide the same parameters of the aggregate expansion curves.

The proposed model intends to utilize the trends of the mineral behavior described by the parameters in Eq. (1) to predict the aggregate expansion. Specifically, the parameters $d V_{\max }, p$ and $q$ are calculated as linear interpolations of parameters used for the minerals in aggregates based on the volume fraction of minerals (Algorithm 1).

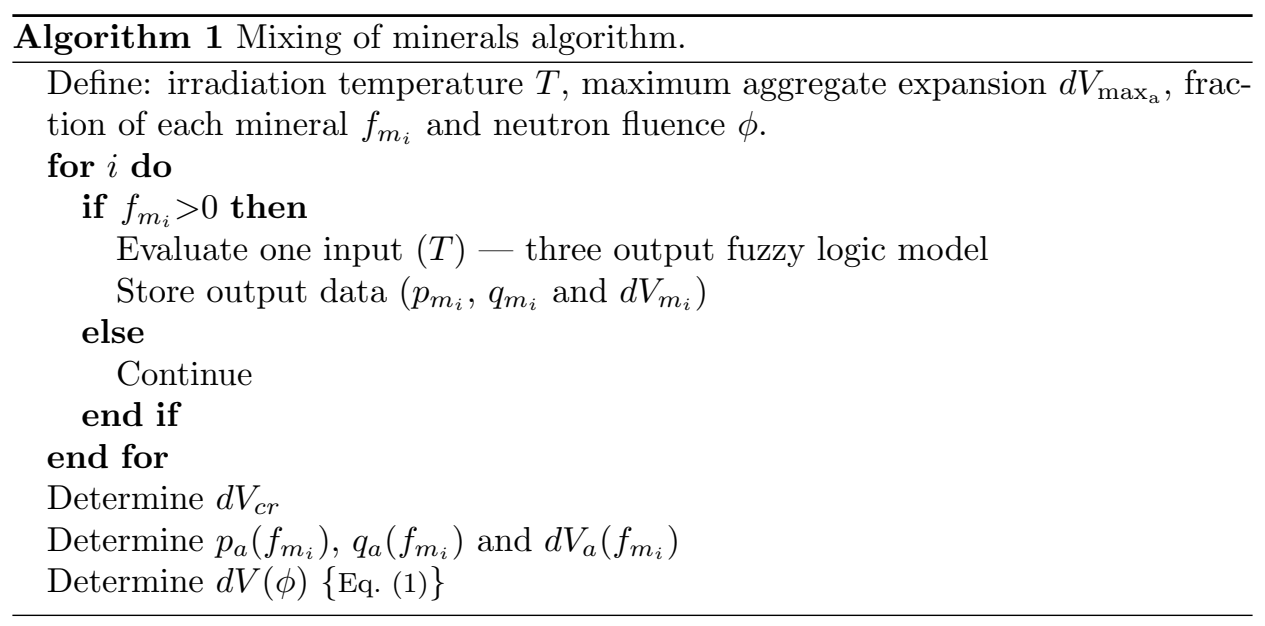

Besides the mineral content, another important parameter which influences the aggregate expansion in the proposed model is temperature. Since the curves for mineral expansion are given within a temperature range, the temperature as an input parameter in the model is fuzzified using triangular membership functions where the temperature range gives the lower and upper limit of the fuzzy number. Nevertheless, for the sake of more general applicability of the model, nonlinear membership functions can also be assumed in the proposed model. However, because of the limited available data, the triangular membership functions are adopted. Moreover, the parameters $d V_{\max }, p$ and $q$ describing the mineral 
Vaitová M., Štemberk P., Rosseel T.M.: Fuzzy logic model of irradiated...

radiation-induced expansion within a specific temperature range are fuzzified, because the temperature itself is a fuzzy number. Generally, the parameter $p$ governing the slope of the sigmoid curve as well as the parameter $q$, which shifts the kick-off point of the sigmoid curve, are dependent on the temperature at irradiation. The parameter $p$ decreases with increasing temperature while the parameter $q$ increases with increasing temperature. Therefore, the lower temperature of irradiation is more detrimental to aggregates and thus the concrete mechanical performance.

Since the cracks constitute a significant portion of the overall expansion of aggregates, the parameter $d V$, which describes the expansion of minerals, needs to be corrected after the calculation, which is based on the volumetric fraction of minerals. Since the experimental data of rocks show the peak of the radiation-induced expansion within just a few temperature ranges, the estimate of the volumetric fraction of cracks in the total expansion can be determined based on the data in [2], which provides a plot that describes the dependence of the increase of the volume due to cracking on the increase of the volume of the rock in total for different rocks. Based on that plot, the correcting coefficient $K_{\text {cr }}$ can be determined from

$$
K_{\mathrm{cr}}=\frac{I}{I-C}
$$

where $I$ is the total increase of the volume of the rock and $C$ is the increase in volume due to cracking. Moreover, the estimate of the crack volume is used in the calculation for the same aggregate but within the temperature range where the peak expansion has not yet been measured. The volumetric fraction of cracks in a particular rock is designated as $d V_{\mathrm{cr}}$.

\section{Model validation}

In order to evaluate the model accuracy compared to experimental data, a method to evaluate such a model is developed. Since the fuzzy logic model of radiationinduced expansion of aggregates gives the boundary curves of each temperature range, the data between the curves are assumed to be the results with no errors as indicated in Figs. 8-10. However, the data outside the boundary curves do contain errors. Each data point error is evaluated twice to get the errors for both boundary curves. The minimum error is then used in the calculation of the mean model error ME using the following equation

$$
\mathrm{ME}=1-\frac{\sum_{i=1}^{n}\left|\frac{f_{i}-y_{i}}{y_{i}}\right|}{n},
$$

where $n$ is the number of data points, $f_{i}$ is the output of the aggregate radiationinduced expansion model function (corresponding to the curve nearest the data point), and $y_{i}$ is the experimentally obtained radiation-induced expansion of the aggregate. The mean error evaluation of the proposed model gives a sense as to how the model is capable of capturing the experimental data and also provides the ability to compare how the model works for different types of aggregates. 
Neural Network World 1/2019, 1-18

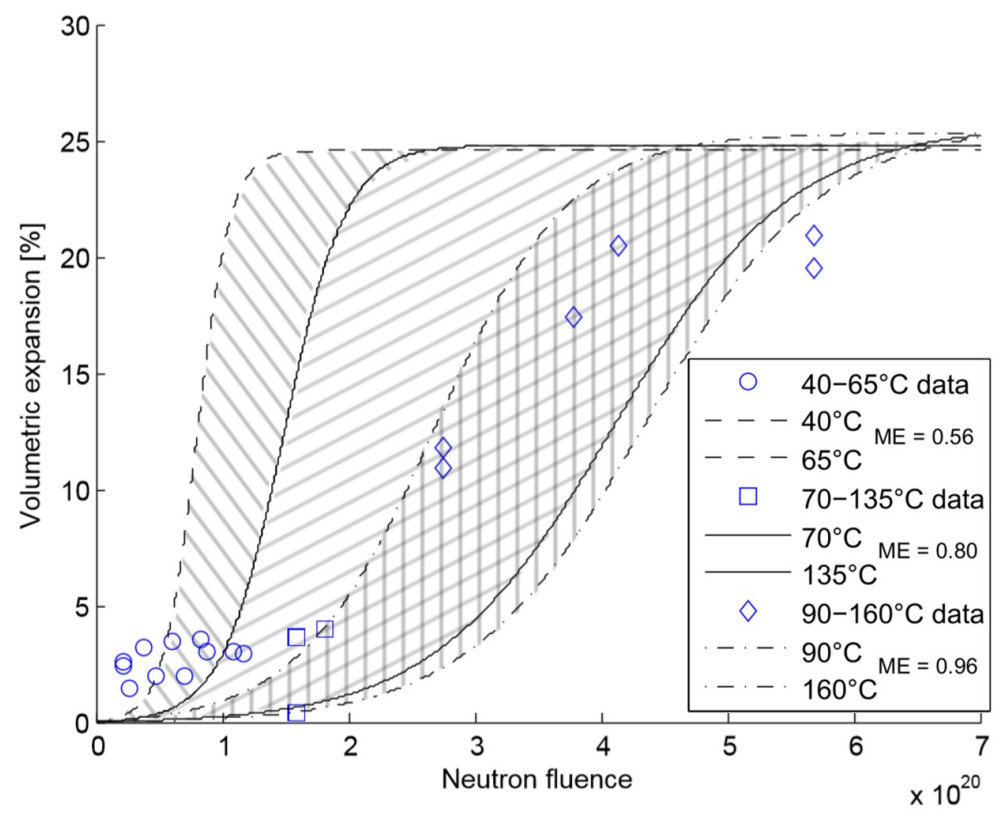

Fig. 8 Granite - validation.

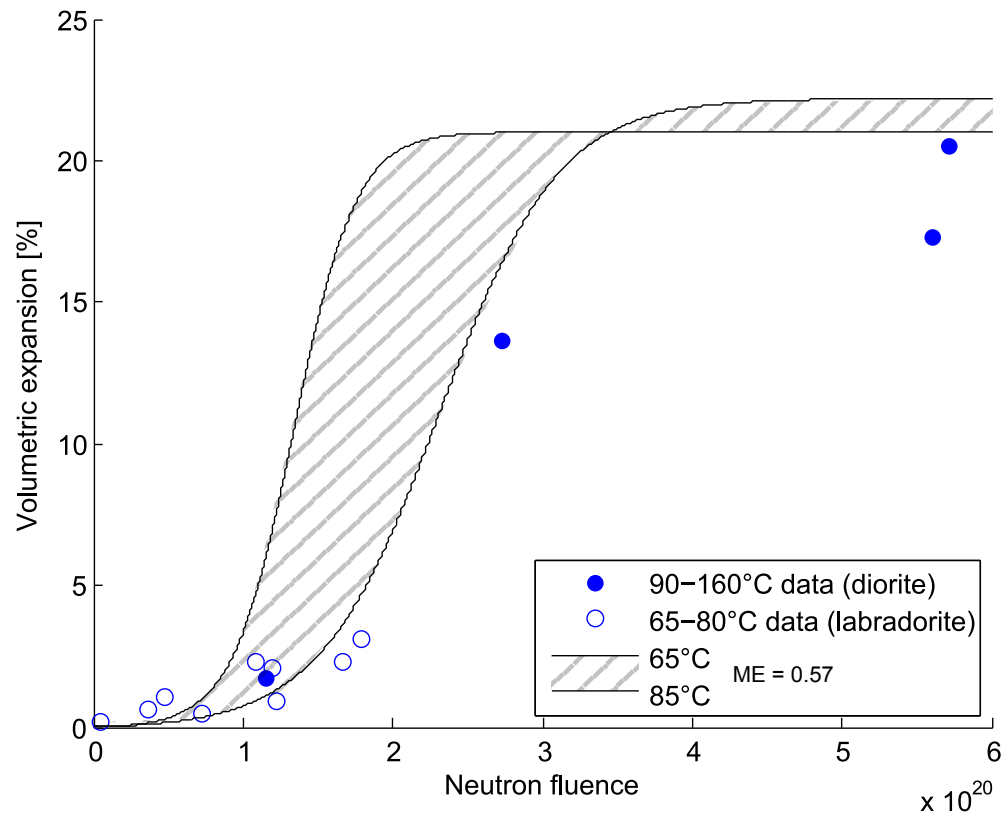

Fig. 9 Diorite (Labradorite) - validation. 
Figs. 8-10 show the results for different aggregates in different temperature ranges. For each temperature range, two boundary curves of radiation-induced expansion of aggregates are determined to provide an estimate of the possible results within the temperature range. The experimental data plot in the same figure as the model curves provides a comparison between the model and experimental data available for the given temperature range based on $\mathrm{ME}$.

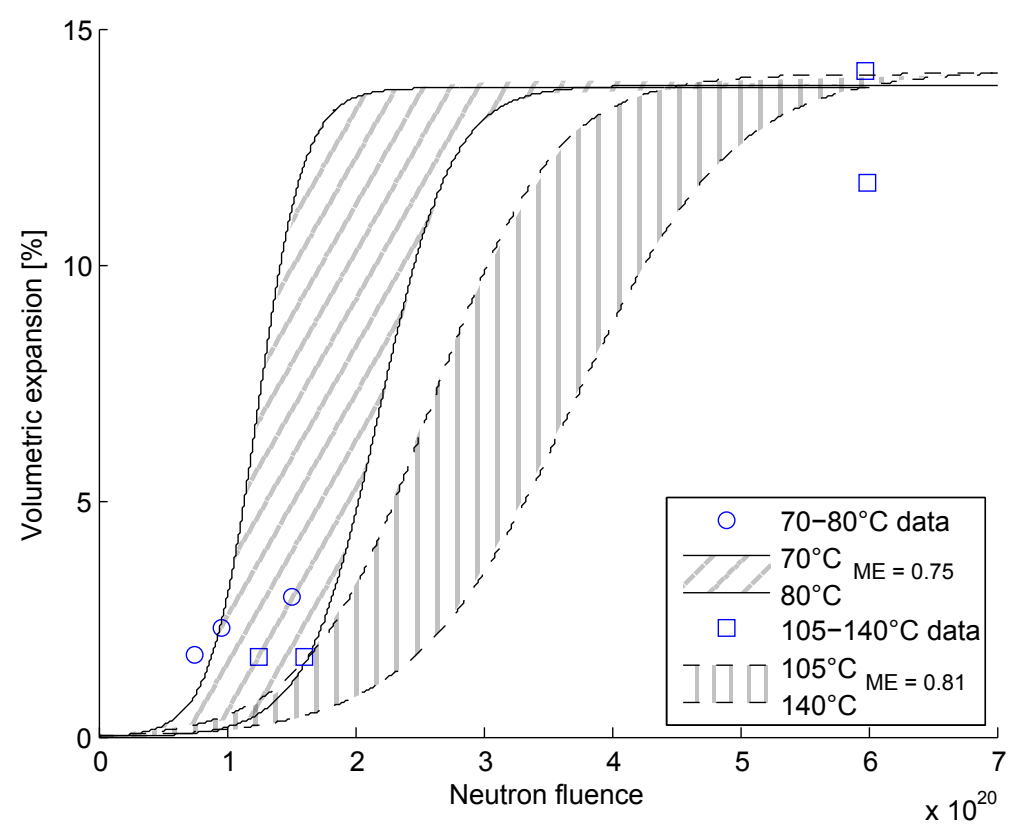

Fig. 10 Gabbro - validation.

The values used for mineral expansion curves are listed in Tab. II, the mineral composition of aggregates are listed in Tab. III and the resulting parameters for aggregates are listed in Tab. IV. It should be noted that in the case of diorite the experimental data on labradorite were used to supplement the experimental data on diorite at low irradiation temperatures.

\begin{tabular}{lccc}
\hline Silica minerals & Gabbro & Granite & Diorite \\
\hline quartz & 0.00 & 0.25 & 0.00 \\
potassium feldspars & 0.60 & 0.50 & 0.75 \\
plagioclase feldspars & 0.00 & 0.24 & 0.05 \\
pyroxenes & 0.40 & 0.00 & 0.15 \\
biotite & 0.00 & 0.01 & 0.05 \\
\hline
\end{tabular}

Tab. III Mineral fraction in aggregates. 


\begin{tabular}{lccccc}
\hline Aggregate & $\mathrm{T}\left[{ }^{\circ} \mathrm{C}\right]$ & $K_{\mathrm{cr}}$ & $d V_{\max }$ & $p$ & $q$ \\
\hline Gabbro & $70-140$ & 2.8 & $13.7-14.1$ & $1.6-5.5 \times 10^{-20}$ & $1.4-3.7 \times 10^{20}$ \\
Granite & $45-160$ & 2.5 & $24.6-25.7$ & $1.4-7.5 \times 10^{-20}$ & $0.8-4.4 \times 10^{20}$ \\
Diorite & $90-160$ & 3.4 & $21.0-22.6$ & $2.5-4.8 \times 10^{-20}$ & $1.3-2.31 \times 10^{20}$ \\
(Labradorite) & $(65-85)$ & & & & \\
\hline
\end{tabular}

Tab. IV Example of resulting parameters of radiation-induced aggregate expansion.

\section{Ready-to-use RIVE estimates}

The proposed model was tested on three different aggregates: granite, gabbro, and diorite as shown in Figs. 11-13.

In the case of granite (Fig. 11), the model captured experimental data for temperatures above $70^{\circ} \mathrm{C}$. For the temperatures between $40-65^{\circ} \mathrm{C}$, the model captured the data only partially, which was caused by the small $R^{2}$ of potassium feldspars at $45^{\circ} \mathrm{C}$ due to the limited data points at that temperature. The results of the gabbro model (Fig. 12) are worse than for granite, which is caused by the very limited input dataset of pyroxene minerals. The last aggregate tested with the model is diorite (Fig. 13). Since the data on diorite expansion are only for high temperatures, labradorite with the similar content of $\mathrm{SiO}_{2}$ was used for estimation of diorite expansion at lower temperatures. Then, with very high $R^{2}$ (with the only exception being potassium feldspars at $45^{\circ} \mathrm{C}$ ), the model in the case of diorite/labradorite has very good correlation with the experimental data.

The proposed model captures trends in aggregate expansion behavior upon irradiation. Firstly, the model is based on individual mineral expansion so the lower $R^{2}$ of the mineral expansion curve affects the ME of the resulting aggregate

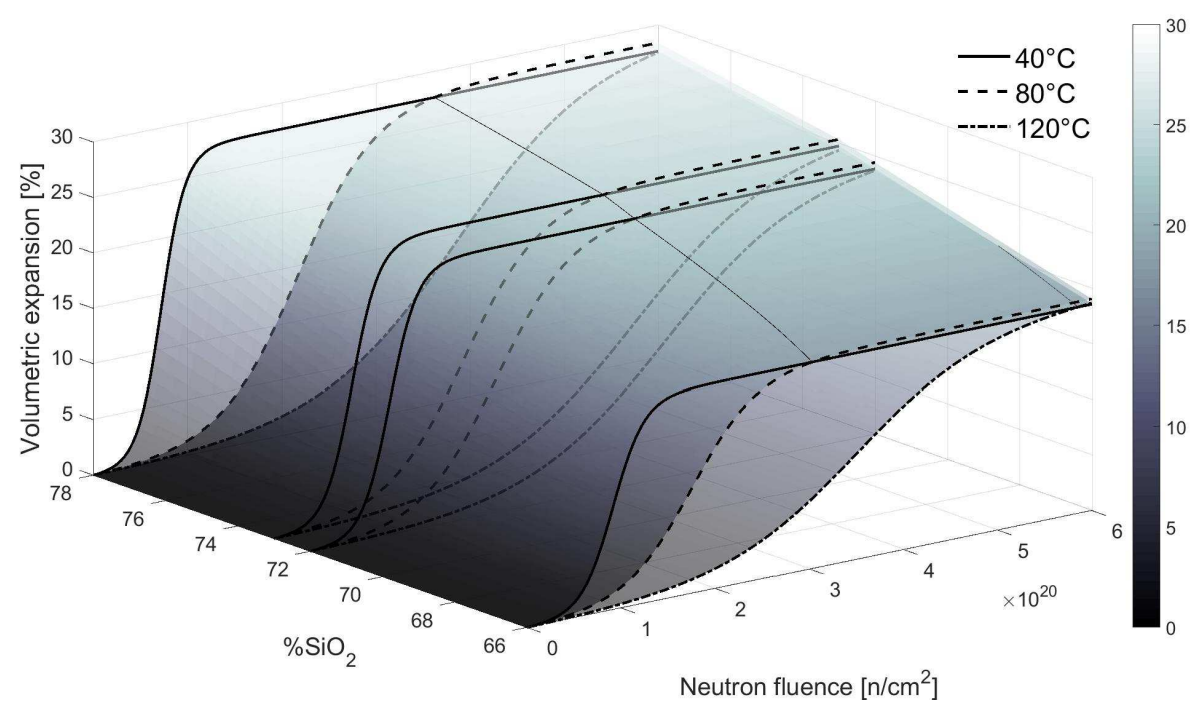

Fig. 11 Granite - estimated RIVE. 
Vaitová M., Štemberk P., Rosseel T.M.: Fuzzy logic model of irradiated...

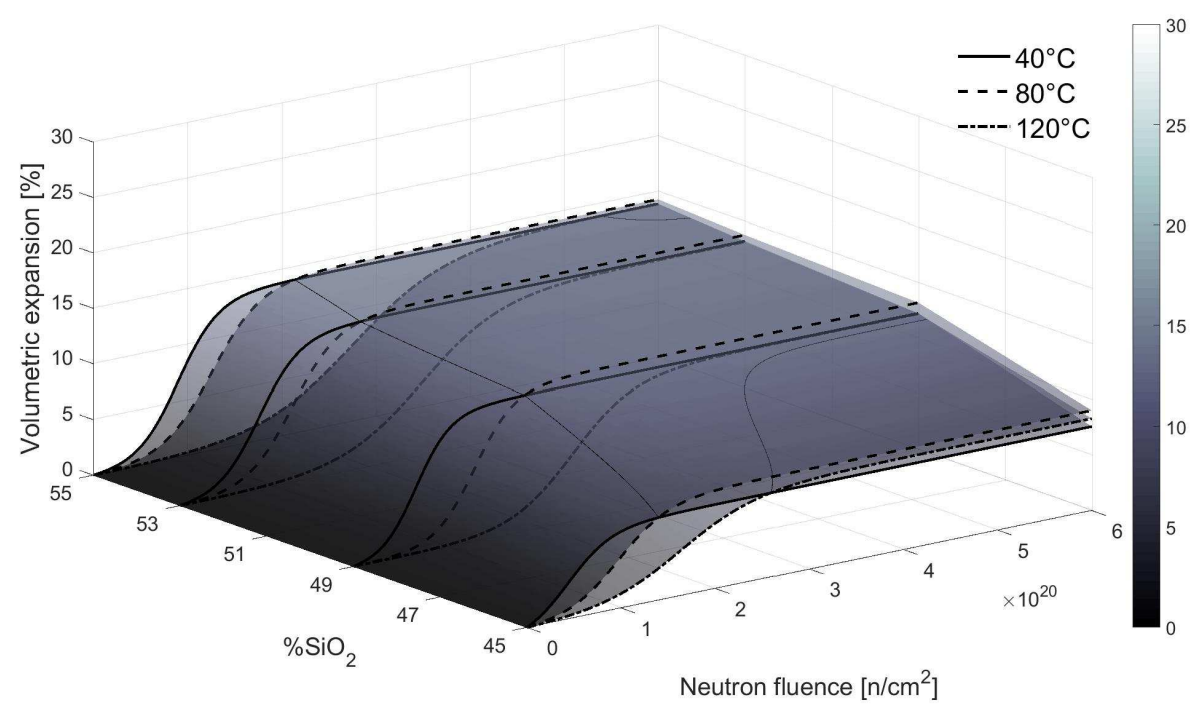

Fig. 12 Gabbro - estimated RIVE.

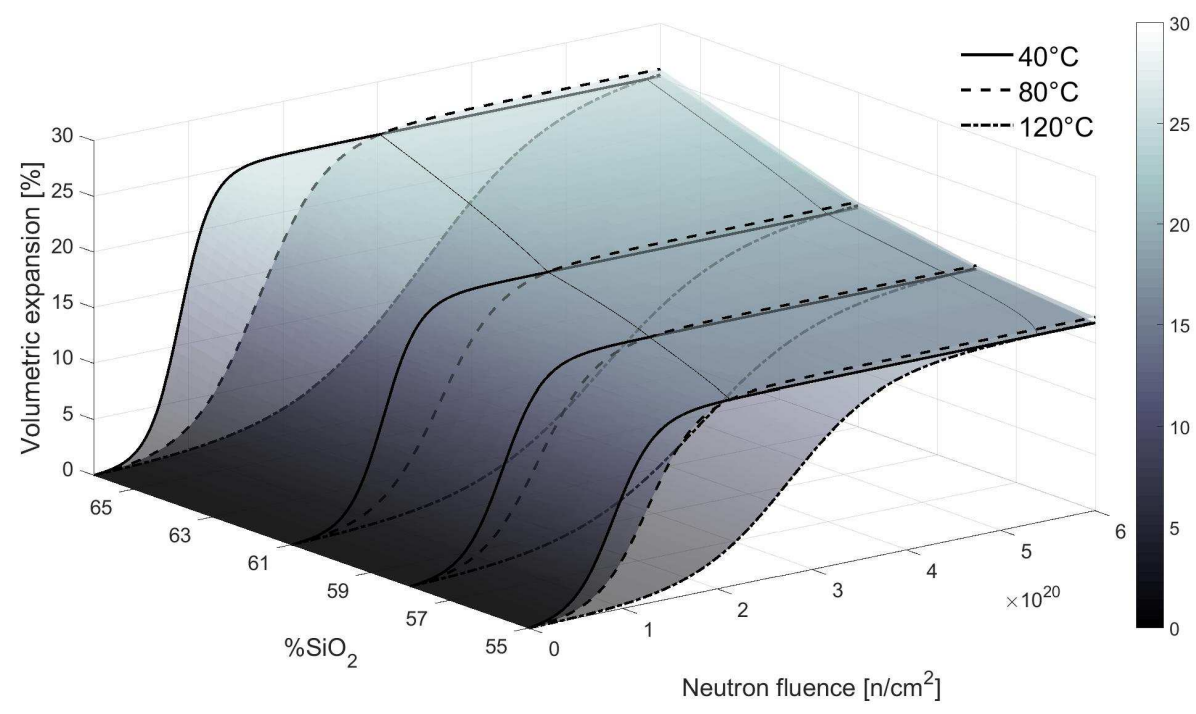

Fig. 13 Diorite - estimated RIVE.

expansion curve. The low $R^{2}$ is due to the limited data for that particular mineral or the specific temperature range of mineral expansion. This is especially apparent in the case of pyroxenes and potassium feldspars at $45^{\circ} \mathrm{C}$. The $R^{2}$ is low which results in a low ME for aggregates containing these minerals. Secondly, the aggregate structure that is given by the aggregate origin (how it is formed in nature) affects defect formation. For example, sedimentary rocks (cementitious) contain more pores than granite or other plutonic magmatic rocks (compaction). Therefore, the 
interconnection between the minerals contained in the rock should be incorporated into the model in order to obtain more realistic data. For this reason, the model clearly works better for compacted and well-crystallized aggregates than it would work for cementitious aggregates. For cementitious rocks, the kinetics of RIVE of minerals with respect to the neutron fluence should be assumed.

\section{Conclusions}

The model of irradiated aggregate expansion based on the mineral content of the aggregate is presented in this paper. The results obtained with this model provide an estimate of the aggregate radiation-induced volumetric expansion considering the mineral content, the temperature during irradiation and the neutron fluence, which is the actual dose of neutrons causing damage to the biological shield structure. The aggregate expansion estimates may be used in the meso-scale modeling of concrete for determination of the reduction of concrete mechanical properties. Based on that information, the irradiated concrete structure performance can be assessed.

The trends in the material behavior and the uncertain descriptions of the experimental data provided an opportunity to use the fuzzy logic to evaluate the available information on irradiated minerals. Because of the limited experimental data, the model should not use the classical homogenization approaches usually used for heterogeneous materials.

The results presented in this paper show good correlation between the proposed model and the experimental data mainly for compact and well-crystallized aggregates that are typically found in the NPP structures. Therefore, the results of this paper can be also used for assessment of concrete structure conditions during the license renewal process.

\section{Acknowledgements}

This research was supported in part by the U. S. Department of Energy, Office of Nuclear Energy, Light Water Reactor Sustainability (LWRS) Program under contract DE-AC05-00OR22725 with UT-Battelle, LLC, via the Oak Ridge National Laboratory (ORNL) Advanced Short-Term Research Opportunity (ASTRO) Program, which is managed by Oak Ridge Associated Universities (ORAU). This work was also supported by the Czech Science Foundation, project 16-20008S, and the Czech Technical University in Prague, project SGS18/041/OHK1/1T/11, which are gratefully acknowledged.

This manuscript has been co-authored by UT-Battelle, LLC, under Contract No. DE-AC05-00OR22725, with the U.S. Department of Energy. The United States Government retains and the publisher, by accepting the article for publication, acknowledges that the United States Government retains a non-exclusive, paid-up, irrevocable, worldwide license to publish or reproduce the published form of this manuscript, or allow others to do so, for United States Government purposes. The Department of Energy will provide public access to these results 
Vaitová M., Štemberk P., Rosseel T.M.: Fuzzy logic model of irradiated...

of federally sponsored research in accordance with the DOE Public Access Plan (http://energy.gov/downloads/doe-public-access-plan).

\section{References}

[1] COX K., BELL J., PANKHURST R. The Interpretation of Igneous Rocks. 1st ed. London: Chapman \& Hall, 1979. ISBN 9780412534102.

[2] DENISOV A., DUBROVSKII V.B., SOlOVEV V.N. Radiation Resistance of Mineral and Polymer Building Materials. 1st ed. Moscow: Publishing House MEI, 2012. ISBN 9785383006481.

[3] ELLEUCH L., DUBOIS F., RAPPENEAU J. Effects of neutron radiation on special concretes and their components. Special Publication of The American Concrete Institute. 1972, 43, pp. 1071-1108.

[4] FIELD K., REMEC I., LE PAPE Y. Radiation Effects on Concrete for Nuclear Power Plants, Part I: Quantification of Radiation Exposure and Radiation Effects. Nuclear Engineering and Design. 2015, 282, pp. 126-143.

[5] GIORLA A., VAITOVÁ M., LE PAPE Y., ŠTEMBERK P. Meso-scale modeling of irradiated concrete in test reactor. Nuclear Engineering and Design. 2015, 295, pp. 59-73.

[6] HILSDORF H., KROPP J., KOCH H. The effects of nuclear radiation on the mechanical properties of concrete. Special Publication of The American Concrete Institute. 1978, 55, pp. 223-254.

[7] KELLY B., BROCKLEHURST J., MOTTERSHEAD D., MCNEARNEY S., DAVIDSON I. The effects of reactor radiation on concrete. In: Proceedings of the Second Information Meeting on Pre Stress Concrete and Reactor Pressure Vessels and their Thermal Isolation, Brussels, 1969, pp. 237-265,

[8] KONTANI O., ICHIKAWA Y., ISHIZAWA A., TAKIZAWA M., SATO O. Irradiation Effects on Concrete Structure. In: International Symposium on the Ageing Management and Maintenance of Nuclear Power Plants, 2010, pp. 173-182,

[9] NEVILLE A. Properties of concrete. 4th ed. 1996. ISBN 0470235276.

[10] POKORNÁ N., ŠTEMBERK P. Stress-strain Diagram of Hardening and Fiber Concrete Defined by Fuzzy Logic. In: Mechanika 2009 - Proceedings of the 14th International Conference, 2009, pp. 329-333,

[11] RAPPENEAU J., LAGORIO M., GILBERT J., PIRON P. Irradiation Tests of Concretes. Bulletin d'Information Scientifique et Technique. 1966, 110(BNWL-TR21), pp. 31-48.

[12] REMEC I. Status Report on Defining a Unified Parameter for Characterization of Radiation Intended for Evaluation of Radiation-Induced Degradation of Concrete. : Oak Ridge National Laboratory, 2014. Technical report.

[13] ROSSEEL T.M., MARUYAMA I., LE PAPE Y., KONTANI O., GiORLA A.B., REMEC I., WALL J.J., SIRCAR M., ANDRADE C., ORDONEZ M. Review of the Current State of Knowledge on the Effects of Radiation on Concrete. Journal of Advanced Concrete Technology. 2016, 14, pp. 368-383.

[14] SEEBERGER J., HILSDORF H. Einfluss von Radioaktiver Strahlung auf die Festigkeit und Struktur von Beton. : Institüt fur Massiubau und Baustofftechnologie, Arbeitlung Baustofftechnologie, Universität Karlsruhe, Germany, 1982. Technical report NR2505. 
[15] VAitovÁ M., ŠTEMBERK P. Estimation of Ablation Depth in Concrete Slab under Reactor during Nuclear Accident. Neural Network World. 2015, 25(4), pp. 368-383, doi: 10.14311/NNW.2015.25.018. ISSN 1210-0552.

[16] ZUBOV V., IVANOV A. Expansion of quartz caused by irradiation with fast neutrons. Soviet Physics Crystallography. 1966, 11(3), pp. 372-374. 